\title{
FONTES DE INFORMAÇÃO UTILIZADAS POR EXECUTIVOS
}

\section{Silas Marques De Oliveira}

\begin{abstract}
Resumo
O trabalho discute o papel dos sistemas de informação nas empresas, e apresenta as fontes de informação internas e externas mais utilizadas na opinião de 45 gerentes de SI que participaram de um estudo de campo. O estudo apresentado se insere no contexto da informação empresarial e tem como objetivo principal discutir o papel dos sistemas de informação no processo decisório dos executivos, levando em consideração as fontes informacionais externas e internas utilizadas pelos mesmos. Um estudo utilizando questionário realizado entre 45 gerentes de SI de empresas brasileiras revelou que maioria dos sujeitos preferem, com relação a fontes externas, informações oriundas de pessoas em detrimento de informações documentadas formalmente, coincidindo com as fontes internas de maior preferência. Mais da metade, indicaram que consultam seus colegas gerentes de outras áreas da organização para obter informações, indicaram consultar os executivos superiores os subordinados. Fontes de informações documentais eram consultadas por menos da metade dos gerentes de S.I. O estudo conclui que é provável que os gerentes de SI desconheçam o potencial das fontes de informação bem como não possuam instrução adequada para acessá-las ou utilizá-las de forma eficiente.
\end{abstract}

\section{Palavras-chave}

Gestão do Conhecimento; Informação para executivos; Recursos humanos; Sistemas de informação; Comportamento informacional; Fontes externas de informação; Fontes internas de informação;Uso de informação.

\section{INFORMATION SOURCES USED BY EXECUTIVES}

\begin{abstract}
The study inserts in the context of organizational information, and its main objective is to discuss the role of information systems in the executive's decision process, considering internal and external information sources used by executives. A study using questionnaires applied to 45 SI managers of Brazilian organizations revealed that most of the subjects prefer external information originated from people in detriment of documented information, coinciding with the preference for information originated internally. More than half of the subjects indicated that they sought information from colleagues of other departments of the company, consulted their superiors, and their subordinates. Documented information sources were consulted by less than half of the S.I. managers studied. The study concludes that it is probable that S.I managers do not know the potential of the information sources and do not have adequate instruction to access and use these sources effectively.
\end{abstract}

\section{Keywords}

Information Systems; Information behavior; External Information Sources; Internal Information Sources; Information Use. 


\section{INTRODUÇÃO}

As organizações hoje são constantemente desafiadas para se adaptar às mudanças ambientais, levando em consideração as expectativas dos clientes, estratégias competitivas, avanços tecnológicos, leis governamentais, condições instáveis na economia e na sociedade.

A formação e materialização de blocos econômicos, tais como o Mercosul, a Nafta, a Comunidade Econômica Européia, e outros, a dissolução do bloco comunista, a consolidação de potências tecnológicas, a globalização dos mercados financeiros, pressupõem um novo paradigma quanto à função, importância e impacto da informação como fator de competitividade das empresas e organizações em geral, bem como fator determinante de sua adaptabilidade a estas mudanças ambientais.

Conforme D’ercole, (1998) a informação que marcará a competição daqui para frente, é um recurso disponível e democrático. Moresi (2000, p. 14) defende que a "gestão efetiva de uma organização requer a percepção objetiva e precisa dos valores da informação e do sistema de informação”. No entanto, Beraldi (2000, p. 46) é de opinião que “para que as ferramentas, estratégias e informações sejam bem utilizadas, é preciso definir previamente os rumos da empresa”.

Todo este processo de transformação, conforme Borges (1995, p. 181) tem como pano de fundo "a sofisticação tecnológica que rompe limites de tempo e distância, transpondo barreiras sociais, culturais e políticas, tornando o mundo mais integrado”, e para Lastres (1999, p. 74), “ a informação e o conhecimento passaram a se constituir nos recursos básicos do crescimento econômico, em lugar dos tradicionais insumos energéticos e materiais”.

Este novo paradigma quanto à função da informação no ambiente organizacional forçou seus executivos a ter uma visão diferente de seus negócios: como geradores de recursos, como elos pertencentes a uma só corrente econômica, como um órgão da sociedade para a criação de riquezas e como criaturas e criadores do ambiente social - ou seja, a área externa ao ambiente interno da organização na qual oportunidades e ameaças coexistem demandando atenção e energia da organização (DRUCKER, 1995). 
Para fazer frente às necessidades de informação que os executivos necessitam para prosperar neste ambiente mercadológico complexo e mutável, as organizações implementam Sistemas de Informação Executivos (EIS) para agilizar todo o processo de tomada de decisão por parte de seus dirigentes. Estes sistemas são utilizados para acessar notícias, relatórios, patentes, preços, informação sobre concorrentes, clientes, indicadores de desempenho e lucratividade, operações internas, etc.

Qualidade, produtividade e competitividade são conceitos sinalizadores dos atuais desafios das empresas, nos últimos anos. De acordo com Rezende (2002, p. 75), "recentemente, as empresas experimentaram expressivas transformações na gestão dos negócios em conseqüência da automação industrial e de escritórios, de modo que o uso da tecnologia da informação se transformou em passaporte para entrada em um mundo de mercados globalizados”.

No entanto, é necessário que tenhamos cautela, para não exagerar a importância e papel da TI no processo de desenvolvimento das organizações. Pitassi e Leitão (2002, p. 78), alertam que “o mito criado em torno dos benefícios que a tecnologia em geral e a Tecnologia de Informação (TI) em particular inexoravelmente trazem para a humanidade deixa nos mais incautos a sensação de estarmos no limiar de uma nova sociedade, já denominada economia da informação [...]”.

Tendo a importância dos Sistemas de Informação como pano de fundo, este trabalho tem como objetivo principal discutir o papel dos sistemas de informação no processo decisório dos executivos, levando em consideração as fontes informacionais externas e internas utilizadas pelos mesmos.

\section{O PAPEL DOS SISTEMAS DE INFORMAÇÃO}

A idéia de que os executivos ocupados em decidir os destinos de uma empresa necessitam de informação, leva-nos a considerar ser cada dia mais importante o papel dos sistemas de informação, bem como os serviços, produtos e fontes informacionais para as empresas. Porém, tanto a literatura, quanto a prática tem-nos possibilitado constatar que os serviços e produtos de informação, mais notadamente os sistemas de informações gerenciais, não tem atendido às expectativas. (BORGES, 1995) 
Mas esta frustração não é nova, pois os sistemas de informação há quase 20 anos atrás ainda não eram vistos como a fonte mais importante de informações, externas ou internas (JONES; MCLEOD, 1986). Sapiro (1993, p. 108) afirma que "as grandes empresas estão gastando mais dinheiro do que nunca na obtenção de informação, mas muito dinheiro é perdido na construção de ineficientes centros informacionais, baseados em bancos de dados não apropriados ou carregados de informações não relevantes”.

Fuld (1988), citado por Sapiro (1993), apresenta entre cinco outros fatores que determinam o sucesso dos sistemas de informação, ser fundamental a definição das necessidades informacionais, e para Flippo, (1970) o primeiro e mais crucial passo inclui não somente definir a informação necessária, mas também especificar quando e em que formato a informação deverá ser disponibilizada. Os tomadores de decisão devem participar do processo de definição de necessidades e avaliar o valor que a informação terá como ferramenta para a tomada de decisão.

Portanto, para que o planejamento e implementação de serviços, produtos e sistemas de informação sejam eficientes, é fundamental que se conscientize o usuário, no caso o executivo que irá tomar as decisões, de que, para que tais ferramentas atendam à suas necessidades informacionais, cabe a ele torná-las conhecidas. Para isso, o usuário precisa saber definir com clareza as suas atividades, reconhecendo que elas fazem parte de um contexto organizacional amplo e complexo, cujos objetivos devem ser atingidos em função do mercado, da concorrência, do cliente, do fornecedor (BORGES, 1995).

Embora o trabalho de Wilson (1994) apresente vários resultados de estudos identificando os tipos de informações necessárias por diferentes organizações, não apresenta e nem discute questões metodológicas sobre a pesquisa de necessidades, limitando a indicar que as situações que dão origem às necessidades de informação podem ser diversas dependendo do tipo de indústria. Afirma também, que "necessidade de informação não é tanto uma necessidade inerente ao ser humano, mas sim uma resposta a uma situação onde falta a base para a tomada de decisão” (WILSON, 1994, p. 121). 
Para Bertolucci (1996), um sistema de informação deve ser inclusivo e a meta deve ser criar um sistema “na medida” que sirva os usuários em suas necessidades específicas, tanto de acesso quanto de manutenção. Em sua opinião, "para que o sistema seja aceito, como parte integral da companhia, deve ser compatível com a cultura da mesma, e não o contrário” (BERTOLUCCI, 1996, p. 34). Sendo assim, qualquer tipo de informação possui valor apenas na medida em que ela serve a missão da companhia, e para tanto, é imprescindível que o gerente de S.I. determine as fontes de informação mais adequadas para atender as necessidades informacionais dos executivos de sua organização.

\section{FONTES DE INFORMAÇÃO}

Diversas pesquisas relatadas na literatura identificaram as fontes de informação mais utilizadas por gerentes e executivos. Daft e Lendel (1986) categorizaram as fontes em informação externa e interna. Os periódicos e jornais da área comercial, amigos na indústria e clientes foram vistos como fontes importantes de informação externa. Reuniões não agendadas, reuniões formais e “passeios” pela empresa foram tidas como fontes valiosas de informação interna. Já Borges (1995) indica que equipes de vendas e de engenharia, os canais de distribuição, os fornecedores, as agências de publicidade, os concorrentes, encontros profissionais, as associações comerciais, as empresas de pesquisa mercadológica são as principais fontes.

Choo (1994) relata um estudo das fontes de informação utilizadas em “environmental scanning” por executivos da indústria de telecomunicações do Canadá e enfatiza que os executivos responsáveis pela sobrevivência e desempenho de suas organizações devem manter-se bem informados sobre os desenvolvimentos e mudanças ambientais.

“Environmental scanning” é a aquisição e uso de informação sobre os eventos e tendências do ambiente externo à organização, o conhecimento que ajudaria o executivo a planejar as futuras ações do empreendimento. "Scanning” envolve a busca por informação sobre uma questão específica de mercado, assim como estar exposto à informação sem que haja uma necessidade específica por informação.

(c) Revista Digital de Biblioteconomia e Ciência da Informação, Campinas, v. 1, n. 2, p. 18-40 , jan../jun. 2004 - ISSN: 1678-765X. 
“Scanning” pode abranger desde uma simples observação casual de uma reclamação feita por um cliente como uma pesquisa de mercado para determinar a demanda e aceitação de um produto/serviço. Portanto, “Scanning”, constitui-se em um método de busca de informação.

É lugar comum ressaltar que os executivos preferem fontes informais de informação sobre as formais (documentadas). Mas talvez isto seja devido ao fato de que eles possam assim obter “mais” que informação, opiniões, reações, intuições e até apoio moral (KAYE, 1996).

Daft e Lengel (1986) propuseram uma noção (modelo) denominado de fontes de informação “lean” e “rich” ("lean” significa magro, sem gordura; e "rich”, significando rico, abundância, excesso). Este modelo é baseado na noção de que a estrutura da organização afeta o processamento da informação, e tais estruturas podem ser divisadas para facilitar este processamento, e assim, reduzir incerteza. Daft e Lengel se aproveitaram desta noção e ajuntaram o elemento “incerteza” com o elemento, não menos importante, “equivocabilidade” da informação, de tal forma que ambos são considerados como centrais ao dilema das organizações.

Incerteza significa simplesmente a ausência da informação, a onde equivocabilidade significa que mesmo estando a informação disponível, seu significado é ambíguo em um determinado contexto e situação. De acordo com estes autores, as fontes "lean” tais como documentos formais, dados numéricos, etc., servem mais para reduzir o grau de incerteza; as fontes “rich” de informação, tais como, “rumores”, reuniões, contatos pessoais face-a-face, conversas telefônicas, são necessárias para reduzir a equivocabilidade, porque elas estimulam e facilitam o debate e o esclarecimento de questões, e capacitam os executivos a evocarem uma percepção comum e funcional dos problemas, dilemas e contextos do ambiente de trabalho.

Daft e Lengel (1986) propõem diversos mecanismos estruturais, variando dentro destes aspectos, desde os mais “lean” até os mais “rich”, que sejam apropriados para reduzir tanto a incerteza quanto a equivocabilidade. Um exemplo de tal mecanismo, é o papel do “integrador”, isto é, a pessoa que possui uma atividade de "boundary spanning” (o indivíduo que, devido às suas funções, está sempre em contato com pessoas de outros setores da organização, assim continuamente expandindo fronteiras ao se comunicar com seus colegas em outras funções). Estes “integradores” transmitem 
informações e facilitam a comunicação e discussão de questões chaves, e portanto, ajudam a reduzir a equivocabilidade.

O gerente de informação é o candidato natural para assumir tal papel. Tal função expande sua atividade, vai além de suprir e coordenar a informação através de canais formais (“lean”) e inclui seu envolvimento no espectro mais "rico" da atividade informacional. Como normalmente é função dos executivos lidar com a questão da equivocabilidade ao tomarem decisões estratégicas, a função do “integrador” colocaria o gerente de informação mais perto do poder.

\section{ESTUDOS DE NECESSIDADES E USO DA INFORMAÇÃO POR EXECUTIVOS}

Os investigadores também buscaram identificar as principais fontes de informações utilizadas pelos executivos. As fontes mais importantes e mais utilizadas foram os jornais, periódicos da área e a comunicação verbal com colegas. Surpreendentemente, nem todos usavam informações via on-line, e dificuldades em relação a custos e tecnologia foram tidos como os principais responsáveis (OPPENHEIM, 1997, p. 240-242).

A maioria das soluções apresentadas diz respeito diretamente às funções do gerente de S.I. Ele possui a responsabilidade de coletar, filtrar e canalizar informações aos executivos que realmente venham agregar valor ao seu negócio e não servir de barreira ao seu sucesso. A utilização de uma metodologia correta e eficiente de identificar necessidades de informação parece ser um passo fundamental e indispensável para oferecer informação relevante aos executivos e agilizar todo o processo de tomada de decisão.

Baseado nas respostas de 470 questionários enviados a executivos de pequenas empresas inglesas, Smith (1996, p. 39) argumenta que pouco se sabe sobre as necessidades e uso de informação por pequenas empresas bem como a relação que existe entre o bom uso da informação e o nível de sucesso. Os resultados mais relevantes deste estudo foram: 42\% das empresas possuíam um bibliotecário em seu quadro de pessoal; 58\% das empresas bem sucedidas usam um "information broker”; 75\% das empresas bem sucedidas usam a Internet como fonte de informação; os relatórios de “stockbrokers” são as principais fontes de informação e apenas 8\% das empresas bem sucedidas 
afirmaram que usam as informações dos relatórios contábeis. Outro dado interessante, é que as empresas com melhor índice de desempenho não consideram os custos de coleta e análise de informação como sendo uma barreira para seu uso.

Muitos executivos, de acordo com Butcher (1997) continuam dependentes de seus próprios sistemas de informação, muitas vezes ignorando os sistemas existentes em suas empresas. Com freqüência duvidam e questionam a relevância de suas unidades estratégicas e departamentos de pesquisa, e poucos deles consideram a biblioteca ou unidade de informação como uma fonte de informação.

Sendo que os responsáveis por estes sistemas atestam estarem oferecendo o melhor e mais atualizado serviço possível utilizando tecnologia de ponta e pessoal altamente treinado, o problema, portanto, deve residir na falta de conhecimento dos executivos de como usar o sistema devidamente ou não conhecem todo seu potencial. A solução, portanto, se torna óbvia - treinar e conscientizar os executivos através de uma campanha de RP e providenciar explicações do que o sistema é capaz de oferecer-lhes bem como instruí-los em como utilizar a informação disponível.

Embora a falta de uso dos sistemas informais seja tão notória, está bastante claro que os executivos estão usando informação, e de fato, pesquisas de usuários indicam que eles estão cientes de que suas necessidades por informação serão ainda maiores no futuro.

A questão é: por que então os executivos preferem fontes informais e negligenciam as fontes de informação formais? Para responder a esta pergunta é necessário analisar questões que fogem do escopo das fronteiras tradicionais das disciplinas da informação. É necessário analisar o usuário, ou seja, o próprio executivo. Os levantamentos de necessidades de usuários tradicionais não são instrumentos de pesquisa apropriados para este propósito. É necessário investigar os hábitos de busca e coleta de informação dos executivos e realizar mudanças nos sistemas existentes. É necessário considerar os diferentes tipos de tarefas que os executivos executam em suas organizações. Estas tarefas podem ser categorizadas em três tipos diferentes: 
- Tarefas operacionais: estas são as mais básicas, como produção e vendas;

- Tarefas de controle: tais tarefas garantem que os recursos sejam utilizados eficaz e eficientemente no processo de alcançar as metas;

- Tarefas estratégicas: tais tarefas incluem planejamento para o futuro.

O próximo passo seria identificar que tipo de informação é necessário para que o executivo exerça cada uma destas tarefas, levando em consideração que a provisão de informação exaustivamente, considerada como uma virtude a ser perseguida pelas unidades de informação, pode ser considerada como sendo “overload” para os executivos.

McKenney e Keen, (1996) relatam pesquisas sobre o estilo cognitivo de uso de informação sob duas dimensões: coleta de informação e avaliação da informação. De acordo com os autores, a coleta de informações está relacionada ao processo de percepção através do qual a mente organiza o estímulo verbal e não verbal difuso que ela encontra. A “informação” advinda deste processo é o resultado de uma codificação complexa que é fortemente dependente da mente, capacidade de memória, e estratégias, muitas vezes inconscientes - que serve para facilitar o esforço cognitivo.

Os autores identificaram dois estilos de coleta de informação: preceptivo e receptivo. Os indivíduos preceptivos filtram a informação utilizando-se de preceitos, isto é, conceitos e expectativas internalizadas. Eles buscam relações entre os dados e testam informação por seu grau de congruência dos preceitos. Por outro lado, os indivíduos receptivos são sensíveis a qualquer estímulo e tendem a se concentrar nos detalhes e não nas relações (MCKENNEY; KEEN, 1996).

A dimensão de avaliação da informação se refere aos processos de resolução de problemas. Os indivíduos não só diferem com respeito ao seu método de coletar informação mas também com respeito à seqüência de análise dos dados. Assim, dois estilos de avaliação da informação são propostos: o sistemático e o intuitivo. Os indivíduos sistemáticos tendem a impor sob os problemas a estrutura ou método que eles esperam que produzirão uma solução, enquanto que os intuitivos estão mais propensos a usar o método de tentativa e erro, descartam dados e agem de formas imprevisíveis. A combinação destes estilos produzem quatro modelos distintos de busca e avaliação de informação (MCKENNEY; KEEN, 1996). 
Este modelo geral sugere que indivíduos que ocupam diferentes funções gerenciais se encaixam com um destes estilos; assim, o gerente de produção provavelmente seja um sistemático-preceptivo, enquanto que um gerente de propaganda seja mais intuitivo e receptivo. Se este modelo geral tiver fundamento, ele poderá ajudar a explicar porque diferentes membros das organizações requerem, necessitam, reagem e usam informação de formas diferentes (MCKENNEY e KEEN, 1996).

\section{Quadro 1 - Modelo de busca e avaliação da informação}

Busca e Avaliação da Informação

\begin{tabular}{|l|l|l|}
\hline & Sistemática & Intuitiva \\
\hline Preceptiva & & \\
\hline Receptiva & & \\
\hline
\end{tabular}

Fonte: (Kaye, 1996)

\section{METODOLOGIA DA INVESTIGAÇÃO}

Este trabalho visa identificar as fontes de informação externas e internas utilizadas por gerentes de S.I. de empresas brasileiras tendo em vista a maior eficácia dos Sistemas de Informação como apoio ao processo decisório dos executivos.

Diante do objetivo proposto, consideramos a presente pesquisa um estudo exploratório descritivo, onde se utilizou questionários procurando, através da análise dos resultados, uma maior compreensão e percepção das práticas de gerentes de S.I. ao utilizarem fontes de informação para alimentar os S.I. e embasar o processo decisório dos executivos. Esta discussão, indispensável para a compreensão da essência desta prática gerencial é carente de pesquisas formais na área, embora haja inúmeros trabalhos relatados na literatura, conforme parcialmente visto neste estudo, sobre a importância, necessidades, tipos e usos que os executivos fazem da informação para a execução de suas tarefas administrativas.

O universo da pesquisa foram os gerentes de Sistemas de Informação de empresas. Estes gerentes são/eram alunos do Curso de Mestrado em Informática do Instituto de Informática da Pontifícia 
Universidade Católica de Campinas. Do total de 170 alunos inscritos e, portanto, formadores da população deste estudo, 45 responderam ao questionário, formando, portanto, uma amostra de $26 \%$.

Os dados foram levantados através de um questionário dividido em duas partes. A primeira designa identificar as características do S.I. bem como os sujeitos que os gerenciam, ou seja, dados pessoais. A segunda parte do questionário visou identificar as fontes de informação externas e internas utilizadas pelos gerentes de S.I.

Uma carta explicitando os objetivos da pesquisa bem como o questionário para o levantamento dos dados foram enviados a todos os sujeitos desta pesquisa.

Um pré-teste do questionário foi realizado entre 10 gerentes selecionados aleatoriamente para o refinamento do instrumento proposto. Após 30 dias uma nova carta enfatizando a necessidade da colaboração foi enviada a todos que não responderam durante aquele período. Após 30 dias deu-se por encerrado o levantamento, tabulando-se os dados dos questionários recebidos de volta e devidamente preenchidos.

Após a tabulação dos mesmos, procedeu-se a comparação entre os aspectos levantados, demonstrando os resultados em tabelas, enfatizando coincidências e divergências entre os resultados obtidos das diversas empresas.

\section{RESULTADOS}

Nesta seção os resultados obtidos através de 45 questionários respondidos serão apresentados e os principais achados discutidos. As respostas oferecidas pelos gerentes de SI serão apresentadas e discutidas tendo em mente os objetivos deste estudo. 


\subsection{Procedência dos Sujeitos}

Embora os sujeitos desta investigação eram compostos de alunos do Curso de Mestrado em Informática da PUC de Campinas/SP por ocasião do desenvolvimento da pesquisa, executavam suas funções como gerentes e diretores de SI em empresas localizadas em diversas partes do Brasil, o que enriquece a análise dos dados, apesar da “amostra”, por ser intencional, não permitir uma generalização das conclusões. A Tabela 1 apresenta a relação de cidades representadas neste estudo.

Tabela 1 - Cidades de Procedência dos Sujeitos

\begin{tabular}{|c|c|}
\hline FInNDE & EDENITENTIA \\
\hline São Paulo, SP & 06 \\
\hline Sorocaba. SP & 04 \\
\hline Campinas, SP & 02 \\
\hline São João da Boa Vista. SP & 02 \\
\hline Jundiaí. SP & 02 \\
\hline Barueri. SP & 02 \\
\hline Itmbiara. GO & 02 \\
\hline Goiânia. GO & 02 \\
\hline Rio de Janeiro. RJ & 02 \\
\hline Piracicaba. SP & 01 \\
\hline Presidente Prudente. SP & 01 \\
\hline Baurú.SP & 01 \\
\hline Itapetininga. SP & 01 \\
\hline Jaú. SP & 01 \\
\hline Tupã. SP & 01 \\
\hline Mogi Guacú. SP & 01 \\
\hline Mauá. SP & 01 \\
\hline Birigui.SP & 01 \\
\hline Itapira. SP & 01 \\
\hline Londrina. PR & 01 \\
\hline Ivatuba. PR & 01 \\
\hline Ponta Grossa. PR & 01 \\
\hline Mandaguari. PR & 01 \\
\hline Juiz de Fora. MG & 01 \\
\hline Uberaba. MG & 01 \\
\hline Guaxudé. MG & 01 \\
\hline Itaiaí. SC & 01 \\
\hline São João do Mereti.RJ & 01 \\
\hline
\end{tabular}

Fonte: Dados Coletados

A cidade de São Paulo foi a mais representada dentre as cidades onde atuavam os sujeitos que participaram deste estudo. Um total de 6 sujeitos eram de procedência desta cidade, seguida por Sorocaba com uma representação de 4. Vinte e sete outras cidades foram representadas neste estudo, 
sendo que cada uma foi representada por apenas 02 sujeitos. As outras 19 cidades são locais de trabalho de 01 sujeito cada apenas. O maior número de cidades, ou seja, 15, são municípios do estado de São Paulo, seguida de 04 de Minas Gerais, 03 do Paraná, 02 de Goiás, 1 do Rio de Janeiro e 1 de Santa Catarina.

É natural que por Campinas estar localizada no estado de São Paulo, a maioria das cidades de onde procedem os sujeitos estejam realmente localizadas no Estado de São Paulo, embora existam também alunos de outros estados brasileiros realizando o curso e que serviram de sujeitos para esta pesquisa.

\subsection{Ramo de Atividades dos Sujeitos}

É interessante notar a diversidade de "Ramo de Atividade" a que pertencem as empresas onde os sujeitos trabalhavam. Foi possível identificar 23 diferentes ramos da atividade econômica, sendo a área de Educação a mais representativa, ou seja, 10 dos sujeitos trabalham em Sistemas de Informação de organizações de Ensino Superior, seguido por Indústrias Alimentícias (04) e firmas de Consultoria, registrando também 04 sujeitos. Três sujeitos trabalhavam no setor Bancário e ou Financeiro. Outras áreas identificadas com menor representatividade foram: Governo, Transportes, Bebidas, Cosméticos, Siderurgia, Informática, Metalurgia, Combustível, Seguros, Celulose, Calçados, Energia, Química, Supermercados, Logística, Saneamento e Cooperativas.

Se por uma lado este grande leque de atividades onde os sujeitos atuam não permite comparar nem divisar tendências entre os setores econômicos, limitando de certa forma as conclusões, por outro, permite vislumbrar os resultados de uma forma mais ampla oferecendo talvez um quadro mais completo dos tipos de fontes de informação utilizadas nos setores da economia nacional como um todo.

\subsection{Tamanho da Organização}

Os sujeitos da pesquisa trabalhavam em organizações que possuíam desde 2 funcionários até 35.000, sendo que 21 deles pertenciam a organizações com menos de 11 funcionários. Poucos trabalhavam 
em empresas de médio a grande porte. Empresas com 1200, 1500, 1600, 3500, 20000 e 35000 empregados estão representadas neste estudo.

\subsection{Nível Hierárquico Responsável Pelo SI}

A maioria, ou seja, 35 SI’s se encontravam subordinados, no organograma da empresa, a Diretorias das mais diversas, como, Financeira, Recursos Humanos, Superintendência Administrativa e etc. Quatro se reportavam diretamente a algum Vice-Presidente da organização e 7 diretamente ao Presidente ou Dono. Como era de se esperar, os SIs que se reportam diretamente ao Presidente ou dono pertencem a organizações de menor porte. Parece que quanto maior a organização, mais baixo na hierarquia organizacional se encontram os setores responsáveis pelo fluxo de informações.

Em realidade isto é uma contradição, pois quanto maior for a organização, mais seus executivos deveriam valorizar todo o processo informacional como um recurso para alavancar seu posicionamento no mercado e atingir maior competitividade. Portanto, quanto mais próximo o setor de SI estiver dos principais tomadores decisão, melhores condições este setor terá de contribuir mais eficazmente para o alcance da missão da organização, maior poder de decisão seus gerentes terão, assim como terão uma visão mais global das necessidades de todos os setores que compõem a estrutura organizacional, podendo assim, melhor auxiliá-las quanto à satisfação de suas necessidades informacionais.

\subsection{Fontes Externas Consultadas}

O mercado mundial de informação cresce a um ritmo acelerado e se torna, portanto, cada vez mais vasto. As organizações que pretendem sobreviver diante da globalização que se escancara ininterruptamente à porta dos empreendimentos, precisam identificar e usar as mais variadas manifestações e formatos de informação externa.

Existe mais de dois mil bancos de dados on-line, sem incluir as organizações que vendem informações não eletrônicas ou digitais e as milhões de informações que navegam pela WEB. Assim, é desnecessário enfatizar que os mercados de informação tornam-se fundamentais para a 
sobrevivência da maioria das empresas. A Tabela 2 registra as fontes de informação externas que eram consultadas pelos gerentes de SI para alimentar o sistema.

Tabela 2 - Fontes Externas Consultadas Por Gerentes de SI

\begin{tabular}{l|l}
\hline FONTES CONSULTADAS & F \\
\hline CLIENTES & 36 \\
\hline JORNAIS & 22 \\
\hline CONCORRENTES & 22 \\
\hline BOLETINS ESPECIALIZADOS & 15 \\
\hline PUBLICAÇÕES GOVERNAMENTAIS & 14 \\
\hline PATENTES & 05 \\
\hline
\end{tabular}

Fonte: Dados Coletados

Como pode ser observado na Tabela 2, as fontes externas mais consultadas pelos sujeitos foram os “Clientes”, “Jornais” e “Concorrentes”. É interessante notar que a pesquisa desenvolvida por Miranda (1999) também revelou que os “clientes” foram os que mais influenciaram na formulação de ações estratégicas. Os resultados demonstram claramente que os gerentes de SI que participaram deste estudo preferem informações oriundas de pessoas em detrimento de informações documentadas formalmente.

As organizações tem gasto milhões de dólares em softwares e sistemas de informação voltadas para o cliente. Informações sobre hábitos de compra, preferências, disposição quanto ao preço a pagar, reclamações, freqüência de consumo, nível de lealdade às marcas, nível social, informações demográficas, tais como idade, sexo, grau de instrução, atitudes, etc. tem sido coletadas e disponibilizadas em diversos sistemas especialistas. Estas informações são indispensáveis para monitorar a satisfação dos clientes e suas tendências de consumo e expectativas de atendimento, assim como fazem parte dos dados envolvidos na pesquisa de mercado. Estas informações são tão importantes quanto as financeiras para se determinar investimentos, melhorias, inovações e cancelamentos.

Os jornais também são utilizados de forma acentuada pelos executivos. Talvez estas sejam as informações mais atualizadas e relativamente precisas. Em um mundo caracterizado por mudanças 
bruscas e constantes, possuir dados atualizados sobre o mercado, sobre as tendências econômicas, taxas de câmbio, nível de exportação e importação, taxas de juros e sobre a atuação de concorrentes, dentre outras é imprescindível para o processo decisório e conhecimento do contexto ambiental onde a organização está inserida. Consultas a jornais permitem não apenas se obter informações locais, mas também internacionais.

Metade dos gerentes pesquisados indicaram que os executivos obtêm informações diretamente dos concorrentes. O estudo não investigou as formas utilizadas para tanto, mas estas podem ser adquiridas através de telefonemas, conversas informais, em eventos de “classe”, pesquisa intencional “ïn loco” e outras. As informações provindas diretamente dos concorrentes pode ocasionar problemas de confiabilidade, pois a omissão de algum dado relevante poderá provocar o fracasso de alguma iniciativa ou decisão, mas se for correta, em muito ajudará a empresa se recolocar no mercado ou decidir ficar onde está e confirmar que sua forma de atuação no mercado é a melhor.

As outras três fontes de informação externa, ou seja, Boletins Especializados, Publicações Governamentais e Patentes foram menos utilizadas, conforme os sujeitos desta pesquisa. Estas informações possuem um caráter mais oficial, especializado, e mais confiável. Informações detalhadas sobre um determinado produto, processos de fabricação, exigências legais para sua fabricação e comercialização, incentivos governamentais, indicação de mercados bem como suas exigências, são regularmente divulgadas por este tipo de fontes externas.

Os resultados obtidos neste estudo são semelhantes a outros trabalhos. Diversas pesquisas relatadas na literatura identificaram as fontes de informação mais utilizadas por gerentes e executivos. O estudo realizado por Daft (1986) indicou que os amigos na indústria e clientes foram vistos como fontes importantes de informação externa. Já Borges (1995) indica que equipes de vendas e de engenharia, os canais de distribuição, os fornecedores, as agências de publicidade, os concorrentes, encontros profissionais, as associações comerciais, as empresas de pesquisa mercadológica são as principais fontes. Em seu estudo Aguilar (1967) identificou que os executivos estavam mais interessados nas novidades de mercado, incluindo concorrentes, clientes, fixação de preços, estrutura de mercado e mudança. 
Para eliminar pedidos repetitivos de informação externa, é necessário identificar as necessidades de informação e se antecipar ao processo de investigação e coleta. A fase de levantamento de necessidades de informação é imprescindível porque os gerentes de informação estarão capacitados e exercerão um impacto real nos rumos da organização.

As organizações não conseguirão encontrar toda a informação de que necessitam, ou por ser inacessível ou por ser demasiadamente dispendiosa. Gerentes de informação terão de fomentar e criar condições para que haja uma busca contínua entre diversas fontes externas que possuem potencial de contribuir para o êxito da organização.

A ausência de diversidade nas fontes de informação provavelmente é o fator principal que provoca pontos cegos na investigação do ambiente. Se empresas obtêm todo seu acervo de fontes 'aceitáveis', ‘conservadoras' ou 'oficiais', provavelmente seus gerentes verão muito pouca alteração no ambiente externo. (DAVENPORT, 1998, p. 271).

É fato que grande parte da informação relevante em uma organização advém de fontes pessoais, discussões, rumores, conjecturas e informações não-exatas, difíceis de controlar e gerenciar em sistemas formalizados.

O fato dos gerentes pesquisados terem indicado que os executivos provavelmente preferem fontes “pessoais” pode ser uma conseqüência de vários fatores, tais como: desconhecimento das fontes documentais existentes, falta de preparo e habilidade para lidar com tais fontes, problemas de acesso ou acesso restrito e limitado, falta de confiança nas fontes, facilidade de troca de informações através da rede de contatos e relacionamentos.

\subsection{Fontes Internas Consultadas}

O ambiente interno da organização possui e proporciona inúmeras oportunidades de coleta de informação, haja visto todo o capital intelectual acumulado, existente e disponível diariamente. O volume de troca de informações que ocorre dentro de qualquer ambiente de trabalho é extraordinário, seja em reuniões formais de planejamento, seja através de memorandos e comunicados internos, seja as conversas nos corredores ou na "sala do cafezinho". Sabendo aproveitar e identificar estas mais variadas fontes, o gerente de SI poderá coletar valiosas informações provindas tanto de canais 
informais quanto formais dentro de sua própria organização, e assim, alimentar seu EIS ou algum sistema equivalente com informações ou dados adequados e congruentes com e para o processo decisório de sua organização.

A Tabela 3 indica as fontes internas mais utilizadas pelos gerentes de SI participantes desta pesquisa.

Tabela 3 - Fontes Internas Consultadas Por Gerentes de SI

\begin{tabular}{l|c}
\hline FONTES CONSULTADAS & F \\
\hline OUTROS GERENTES & 38 \\
\hline EXECUTIVOS SUPERIORES & 26 \\
\hline RELATÓRIOS INTERNOS & 23 \\
\hline SUBORDINADOS & 21 \\
\hline ESTUDOS E PESQUISAS & 19 \\
\hline BIBLIOTECAS E CENTROS DE INFO & 10 \\
\hline
\end{tabular}

Fonte: Dados coletados

As fontes internas mais utilizadas são fontes pessoais. Mais da metade dos gerentes de SI indicaram que consultam seus colegas gerentes de outras áreas da organização para obter informações. Fontes de informações documentais eram consultadas por menos da metade dos gerentes de SI.

Assim como a tendência revelada em relação aos hábitos de uso de informação externa, os executivos parecem preferir as fontes informais às formais. É provável que os motivos para tal procedimento e preferência sejam os mesmos já apontados com relação às preferências dos gerentes ao usarem fontes de informações externas.

Embora seja importante utilizar fontes pessoais, informais, deixar de utilizar fontes formais e oficiais da organização pode levar a decisões infundadas e imprecisas, resultando em desgastes desnecessários e resultados aquém do esperado. Os relatórios internos poderão apontar tendências, perspectivas, limitações e a correta interpretação dos dados ou informações contidos neles poderão auxiliar os gerentes a adequar o EIS/SI às reais necessidades de desenvolvimento da organização. 


\section{CONCLUSÃo}

O uso de estudos e pesquisas internas de forma regular e sistemática seria um indicador da relevância dos mesmos bem como um aproveitamento dos investimentos feitos, pois para que servirão os resultados dos estudos e das pesquisas se estes não forem utilizados no processo decisório?

As unidades de informação também podem contribuir de forma marcante e decisiva no futuro da organização e em sua saúde mercadológica, pois este órgão possui todas as condições e estrutura para levantar, filtrar, organizar e disponibilizar as informações relevantes. Embora seja uma fonte interna, ela interage de forma constante com o ambiente externo, extraindo dele os insumos informacionais necessários para o bom andamento da organização. No entanto, percebe-se que os gerentes estudados não fazem uso de forma decisiva das fontes de informação formais existentes na organização. É provável que desconheçam o potencial destas fontes de informação bem como não possuam instrução adequada para acessá-las ou utilizá-las de forma eficiente.

A contribuição mais eficaz que os gerentes de SI e/ou profissionais da informação podem oferecer neste processo é tornarem-se a interface pessoal entre as diversas bases de dados informacionais. Podem agir como elos pivotantes entre os executivos com necessidades de informação e as fontes que possam trazer as informações que auxiliarão no processo decisório. Para tanto, precisarão dialogar e interagir com os executivos. Isto auxilia no desenvolvimento de uma compreensão mais profunda dos negócios e permite adquirirem uma melhor apreciação pelo trabalho, necessidades em constante mudança, e estilos pessoais dos profissionais e executivos a quem servem. Com estas funções, tais profissionais são os elos chaves no "web do conhecimento" vital da organização (SKYRME, 1998).

Assim, não é de se admirar que Drucker (1995) no mesmo ano defendia que a organização fundamentada na autoridade e no controle que surgiu em 1870 podia ser comparada a um organismo que está preso em sua própria concha e que as organizações precisam ser estruturadas tendo como suporte um esqueleto: informação. 
Uma vez tendo identificado estas necessidades, será possível discutir e analisar de forma crítica, a eficácia dos modelos que estão sendo utilizados e compatibilidade dos mesmos em relação ao contexto e especificidades do negócio empresarial verificando se realmente as fontes de informação que estão sendo utilizadas oferecem informações relevantes para otimizar o processo de tomada de decisão do executivo e estabelecer uma política informacional.

Este estudo (1) revelou que existe a necessidade de haver uma melhor integração entre a teoria (discurso) e a prática relativo às questões de coleta e aplicação e uso eficaz da informação competitiva de uma empresa; (2) contribuiu para uma maior compreensão e conscientização da importância dos gerentes de S.I. utilizarem fontes de informação mais apropriadas para melhor satisfazer as necessidades dos executivos; (3) forneceu subsídios para ampliar a discussão sobre necessidade e uso de informação competitiva por parte dos segmentos empresariais e de negócios; e (4) revelou os tipos específicos de informação utilizados por gerentes de S.I.

\section{REFERÊNCIAS}

AGUILAR, F. Scanning the business environment. New York: Macmillan, 1967.

BERALDI, L. C. Impacto da tecnologia de informação na gestão de pequenas empresas. Ciência da Informação, Brasília, v. 29, n. 1, p. 46-50, jan./abr. 2000.

BERTOLUCCI, K. The information audit: an important management tool. Managing Information, v. 3, n. 6, June 1996.

BORGES, M. E. N. A informação como recurso gerencial das organizações na sociedade do conhecimento. Ciência da Informação, v. 24, n. 2, p. 181-188, maio/ago. 1995.

BUTCHER, H. Why don’t managers use information? Managing information. v. 4, n. 4, p. 29-30, May 1997.

CHOO, C. W. Perception and use of information sources by chief executives in environmental scanning. Library and Information Science Research, v. 16, p. 23-40, 1994. 
DAFT, R.; LENGEL, R. Organizational information requirements, media richness and structural design. Management Science, v. 32, n. 4, p. 554-571, May 1986.

DAVENPORT, T. H. Ecologia da informação. São Paulo: Futura, 1998.

D’ERCOLE, R. Dinheiro a conta-gotas. Pequenas Empresas Grandes Negócios. v. 10, n. 110, p. 58-61, maio 1998.

DRUCKER, P. F. The information executives truly need. Harvard Business Review, Jan./Feb. 1995.

FLIPPO, E. B.; MUSINGER, G. M. Management. 5. ed. Boston: Allyn \& Bacon, 1970.

FULD, L. M. Descobrindo os ativos ocultos de informação de sua empresa. IN: FULD, L. M. Administrando a concorrência. Rio de Janeiro: Record, 1988. p. 56-84.

JONES, J. W.; McLEOD, R. The structure of executive information systems. Decision Sciences, v. 17, n. 2, p. 220-249, Spring 1986.

KAYE, D. An information model of organization. Managing Information. v. 3, n. 6, p.19-21, June 1996.

LASTRES, H. M. M. Informação e conhecimento na nova ordem mundial. Ciência da Informação, Brasília, v. 28, n. 1, p. 72-78, jan./abr. 1999.

MCKENNEY J. L.; KEEN, P. G. W. How manager’s minds work, Harvard Business Reveiw, v. 74, n. 3, p. 79-90, 1996.

MIRANDA, R. C. R. O uso da informação na formulação de ações estratégicas pelas empresas. Ciência da Informação, Brasília, v. 28, n. 3, p. 284-290, set./dez. 1999.

MORESI, E. A D. Delineando o valor do sistema de informação de uma organização. Ciência da Informação, Brasília, v. 29, n.1, p. 14-24, jan./abr. 2000.

OPPENHEIM, C. Managers' use and handling of information. International Journal of Information Management, v. 17, n. 4, p. 239-248, 1997.

PITASSI, C.; LEITÃO, S. P. Tecnologia de informação e mudança: uma abordagem crítica. Revista de Administração de Empresas, São Paulo, v. 42, n. 2, p. 77-87, abr./jun. 2002. 
REZENDE, Y. Informação para negócios: os novos agentes do conhecimento e a gestão do capital intelectual. Ciência da Informação, Brasília, v. 31, n. 1, p. 75-83, jan./abr. 2002.

SAPIRO, A. Inteligência empresarial informacioanl: a revolução informacional da ação competitiva. Revista de Administração de Empresas, Rio de Janeiro, v. 33, n. 3, p. 106-124, 1993.

SKYRME, D. J. Knowledge management. oxymorn ou dynamic dou? Managing Information, v. 4, n. 7, p. 24-25, Sept 1998.

SMITH, A. Information and the small company. Managing Information, v. 3, n. 7/8, p. 38-41, July/Aug., 1996.

WILSON, T.D. Tools for the analysis of business information needs. Aslib Proceedings, v. 46, p. 19-23, Jan. 1994. 


\section{SILAS MARQUES DE OLIVEIRA}

Ph.D. e Professor Titular do Curso de Mestrado em Ciência da Informação

Pontifícia Universidade Católica de Campinas, Campinas, SP

Rua Antonio Biassi Filho, 287

13184-040 Hortolândia, SP

(19)3865-2877

e-mail: silasmarques@hotmail.com

e-mail: silas@puc-campinas.edu.br

Artigo aceito para publicação em: 1/11/2003 